\title{
BMJ
}

\section{Chloramphenicol versus ampicillin plus gentamicin for community acquired very severe pneumonia among children aged 2-59 months in low resource settings: multicentre randomised controlled trial (SPEAR study)}

\author{
Rai Asghar, professor, ${ }^{1}$ Salem Banajeh, professor, ${ }^{2}$ Josefina Egas, microbiologist, ${ }^{3}$ \\ Patricia Hibberd, professor, ${ }^{4}$ Imran Iqbal, professor, ${ }^{5}$ Mary Katep-Bwalya, consultant, ${ }^{6}$ \\ Zafarullah Kundi, FRCP professor, ${ }^{1}$ Paul Law, associate professor, ${ }^{7}$ William MacLeod, assistant \\ professor, ${ }^{8}$ Irene Maulen-Radovan, professor, ${ }^{9}$ Greta Mino, professor, ${ }^{10}$ Samir Saha, professor, ${ }^{11}$ \\ Fernando Sempertegui, director, ${ }^{3}$ Jonathon Simon, director, ${ }^{8}$ Mathuram Santosham, professor, ${ }^{7}$ \\ Sunit Singhi, professor, ${ }^{12}$ Donald M Thea, professor, ${ }^{8}$ Shamim Qazi, medical officer,,$^{13}$ for the SPEAR \\ (Severe Pneumonia Evaluation Antimicrobial Research) Study Group
}

${ }^{1}$ Rawalpindi General Hospital,

Rawalpindi, Pakistan

${ }^{2}$ Al-Sabeen Hospital, Sana'a,

Yemen

${ }^{3}$ Corporacion Ecuatoriana de Biotecnologia, Quito, Ecuador

${ }^{4}$ Clinical Research Institute, New England Medical Center Tufts University, Boston, USA

${ }^{5}$ Nishter Hospital, Multan,

Pakistan

${ }^{6}$ University Teaching Hospital,

Lusaka, Zambia

${ }^{7}$ Department of International

Health, Johns Hopkins Bloomberg

University, Baltimore, USA

${ }^{8}$ Center for International Health and Development, Boston

University School of Public Health, Boston, MA 02118, USA

${ }^{9}$ Instituto Nacional de Pediatria,

Division de Investigacíon, Mexico City, Mexico

${ }^{10}$ Children's Hospital, Guayaquil, Ecuador

${ }^{11}$ Dhaka Shishu Hospital, Dhaka, Bangladesh

${ }^{12}$ Post Graduate Institute of Medical Education and Research, Chandigarh, India

${ }^{13}$ Department of Child and Adolescent Health and

Development, World Health Organization, Geneva, Switzerland Correspondence to: D M Thea dthea@bu.edu

doi:10.1136/bmj.39421.435949.BE

\section{ABSTRACT}

Objective To evaluate whether five days' treatment with injectable ampicillin plus gentamicin compared with chloramphenicol reduces treatment failure in children aged 2-59 months with community acquired very severe pneumonia in low resource settings.

Design Open label randomised controlled trial.

Setting Inpatient wards within tertiary care hospitals in Bangladesh, Ecuador, India, Mexico, Pakistan, Yemen, and Zambia.

Participants Children aged 2-59 months with WHO defined very severe pneumonia.

Intervention Chloramphenicol versus a combination of ampicillin plus gentamicin.

Main outcome measures Primary outcome measure was treatment failure at five days. Secondary outcomes were treatment failure defined similarly among all participants evaluated at 48 hours and at 10 and 21 days.

Results More children failed treatment with

chloramphenicol at day 5 (16\% v 11\%; relative risk 1.43 , $95 \%$ confidence interval 1.03 to 1.97 ) and also by days 10 and 21 . Overall, 112 bacterial isolates were obtained from blood and lung aspirates in 110 children (11.5\%), with the most common organisms being Staphylococcus aureus $(n=47)$ and Streptococcus pneumoniae $(n=22)$. In subgroup analysis, bacteraemia with any organism increased the risk of treatment failure at 21 days in the chloramphenicol group $(2.09,1.41$ to 3.10$)$ but not in the ampicillin plus gentamicin group (1.12, 0.59 to 2.13). Similarly, isolation of $S$ pneumoniae increased the risk of treatment failure at day $21(4.06,2.73$ to 6.03$)$ and death $(5.80,2.62$ to 12.85$)$ in the chloramphenicol group but not in the ampicillin plus gentamicin group. No difference was found in treatment failure for children with $S$ aureus bacteraemia in the two groups, but the power to detect a difference in this subgroup analysis was low. Independent predictors of treatment failure by multivariate analysis were hypoxaemia (oxygen saturation $190 \%$ ), receiving chloramphenicol, being female, and poor immunisation status.

Conclusion Injectable ampicillin plus gentamicin is superior to injectable chloramphenicol for the treatment of community acquired very severe pneumonia in children aged 2-59 months in low resource settings.

Trial registration Current Controlled Trials

ISRCTN39543942.

\section{INTRODUCTION}

Pneumonia is a leading cause of death in under $5 \mathrm{~s}$ in low resource settings and accounts for about two million deaths in this age group annually. ${ }^{1-3}$ The World Health Organization recommends standard case management of pneumonia on the basis of disease severity. ${ }^{4}$ Very severe pneumonia - the most advanced form of the disease - is defined as the presence of cough or difficulty breathing, with clinical symptoms and signs of pneumonia and any accompanying danger signs (cyanosis, inability to drink, difficulty in waking, stridor in a calm child $)^{5}$ and carries the highest mortality. ${ }^{6}$ First line treatment for this condition recommended by WHO is injectable chloramphenicol followed by oral chloramphenicol ${ }^{5}$ to treat for the common bacterial pathogens that cause very severe pneumonia: Haemophilus influenzae, Streptococcus pneumoniae, Staphylococcus aureus, and Gram negative bacteria such as Escherichia coli and Klebsiella spp. ${ }^{78}$

Although chloramphenicol may have had some advantages in the past, the increasing resistance of bacteria, particularly $H$ influenzae and $S$ aureus, to this antibiotic adds to the longstanding concerns that it is bacteriostatic and associated with bone marrow toxicity, particularly in malnourished children. ${ }^{9-14}$ An 
Box 1: Study sites

Bangladesh-Bangladesh Institute of Child Health, Dhaka Shishu Hospital, Dhaka

Ecuador-Dr Francisco de Icaza Bustamente Children's Hospital, Guayaquil

India-Post Graduate Institute of Medical Research and Education, Chandigarh

Mexico-National Institute of Pediatrics, Mexico DF, Jaurez Hospital, Mexico City

Pakistan-Rawalpindi General Hospital, Rawalpindi, and Nishter Hospital, Multan

Yemen-Al-Sabeen Hospital, Sana'a University, Sana'a

Zambia-Department of Paediatrics and Child Health, University Teaching Hospital, Lusaka

alternative regimen already being used in some areas, combined ampicillin and gentamicin, is bactericidal and provides good coverage against $H$ influenzae, $S$ pneumoniae, E coli, and Proteus mirabilis. The combination is synergistic and bactericidal against the common Gram negative organisms associated with very severe pneumonia, including E coli, Enterobacter spp, Klebsiella spp, Proteus spp, Serratia spp, and Citrobacter spp. Although in vitro penicillin resistance among $S$ pneumoniae has been reported, ${ }^{10111516}$ this has not been clearly associated with worse clinical outcome in pneumococcal pneumonia. ${ }^{17-21}$

Although the standard case management strategy has successfully decreased pneumonia related mortality, ${ }^{22}$ specific information about the efficacy of chloramphenicol in very severe pneumonia is sparse. ${ }^{24-27}$ In addition to concerns about increasing resistance ${ }^{28}$ or adverse clinical outcomes ${ }^{9}$ diminished clinical response and increasing resistance to penicillin and gentamicin among children with community acquired severe bacteraemic pneumonia has been seen in Congo ${ }^{29}$ and elsewhere.$^{27}$ Only one published study has directly compared the clinical efficacy of ampicillin plus gentamicin with chloramphenicol in young children with very severe pneumonia and found no difference between the two regimens. ${ }^{28}$ The study was, however, limited to one country and not powered to detect less than a $10 \%$ difference between treatment arms.

Given the lack of evidence on regimens other than chloramphenicol, we carried out a multicentre study to determine if injectable ampicillin plus gentamicin is superior to injectable chloramphenicol for the treatment of community acquired very severe pneumonia in children aged 2-59 months in seven developing countries. We chose ampicillin because of its greater activity against $H$ influenzae and some Gram negative enteric bacilli, such as $E$ coli and $P$ mirabilis.

\section{METHODS}

Our primary hypothesis was that treatment failure at five days among children aged 2-59 months with WHO defined very severe pneumonia was greater for parenteral chloramphenicol than it was for injectable ampicillin plus gentamicin. The primary outcome was treatment failure at five days. Secondary outcomes were treatment failure defined similarly among all participants evaluated at 48 hours and at 10 and 21 days.

This randomised, non-blinded efficacy study was carried out at eight sites in seven countries: Dhaka, Bangladesh; Guayaquil, Ecuador; Chandigarh, India; Mexico City, Mexico; Multan and Rawalpindi, Pakistan; Sana'a, Yemen; and Lusaka, Zambia (box 1). A consensus protocol was developed by investigators from the study sites, WHO, Johns Hopkins University Bloomberg School of Public Health, and the Center for International Health and Development at Boston University School of Public Health.

Study doctors and study nurses at each site were trained on the study protocol and WHO case management for acute respiratory tract infections using WHO training videos and exercises to ensure inter-rater reliability among the study staff. The clinical investigator at each site oversaw and monitored the study staff.

\section{Enrolment}

Box 2 shows the criteria for study inclusion and exclusion. We informed families about the purpose and background of the study, the study procedures, risks, payments, and confidentiality. They were told that they could withdraw their child from the study at any time and that he or she would continue to receive standard medical care provided to children with similar illness in the participating hospital. They were told that during admission to hospital their child would be assessed every six hours or more often if needed, for any change in their condition until there was an improvement in breathing difficulty and satisfactory oxygen levels when breathing room air. They were told about the need for follow-up and when and where to

\begin{tabular}{lcc}
\hline Table 1|Enrolment by study site & & Dates of study accrual \\
Site & No (\%) of children enrolled & Aug 2000 to Apr 2004 \\
Chandigarh, India & $183(19.1)$ & Sep 2000 to Nov 2003 \\
\hline Dhaka, Bangladesh & $203(21.2)$ & Apr 2003 to Mar 2004 \\
\hline Guayaquil, Ecuador & $46(4.8)$ & Apr 2001 to Nov 2001 \\
\hline Lusaka, Zambia & $23(2.4)$ & Sep 2000 to Nov 2003 \\
\hline Mexico City, Mexico & $40(4.2)$ & Oct 2000 to Jun 2003 \\
\hline Multan, Pakistan & $154(16.1)$ & Dec 2000 to Mar 2004 \\
\hline Rawalpindi, Pakistan & $156(16.3)$ & Nov 2000 to Apr 2004 \\
\hline Sana'a, Yemen & $153(16.0)$ & Aug 2000 to Apr 2004 \\
\hline Total & $958(100)$ & \\
\hline
\end{tabular}


Box 2: Inclusion and exclusion criteria

Inclusion criteria
Age 2 to 59 months
History of cough or difficulty breathing, or both
WHO defined very severe pneumonia ${ }^{30}$
Central cyanosis or inability to drink
Caregiver willingness to consent
Exclusion criteria
Wheezing, with a history of three or more attacks, or
known asthma
Known heart disease
Duration of present illness more than 10 days
History of serious adverse reaction to any of the study
drugs
Previous enrolment in the study
Admission to hospital for more than 24 hours within past
seven days
Documented evidence of injectable antibiotic treatment
for more than 24 hours before enrolment
Stridor
Known renal failure or not passed urine during past six
hours
Evidence of cerebral malaria
Evidence of bacterial meningitis
Clinical jaundice
Residence of patient in an area where follow-up was not
possible
Empyema or presence of pneumatocoeles on chest
radiograph

bring the child back to the hospital after discharge to see if they were still infected.

\section{Randomisation}

WHO prepared lists for randomisation using permuted blocks of variable length (6-8-10), with block sizes presented in random order. Separate randomisation lists were prepared for each site according to nutrition status of the children (severely malnourished, defined by $\mathrm{WHO}$ as oedema or severe wasting=weight for height $<70 \%$ ( $-3 \mathrm{z}$ score) or severe stunting=height for age $<85 \%$ ( $-3 \mathrm{z}$ score) versus not severely malnourished, as assessed during the baseline examination), and individual patient assignments were placed in opaque sealed envelopes. After each patient was selected for study, the next envelope in order of study numbers (that is, in numerical sequence) was opened to determine the treatment assignment: thus the investigator could not know the order of randomisation and was unable to predict the next assignment.

Before opening each envelope the doctor in charge signed and dated the opening flap of the envelope. The card inside, with the patient's treatment assignment, and the signed envelope were attached to the patient's study file. To prevent tampering with the randomisation process, envelopes were checked to ensure that the assignment could not be seen before the envelope was opened. During site visits the presence of the signature, date, and time notification was evaluated and compared with the date and time of randomisation recorded in the medical record.

\section{Baseline assessment}

When children were admitted to the hospital we took a standardised baseline history and carried out a physical examination, laboratory evaluations, and chest radiography. Blood was obtained by venepuncture for complete blood count, malaria smear, blood glucose levels, and bacterial culture. Lumbar puncture was done on participants with clinical signs suggestive of bacterial meningitis, and we examined cerebrospinal fluid for total leucocyte count, differential leucocyte count, biochemistry, and bacterial culture by Gram stain.

\section{Case management protocol}

Children received the first dose of antibiotics within two hours of enrolment. Those randomised to the ampicillin plus gentamicin arm received ampicillin $200 \mathrm{mg} / \mathrm{kg} / \mathrm{d}$ in four doses every six hours, and gentamicin $7.5 \mathrm{mg} / \mathrm{kg} / \mathrm{d}$ as in a single daily dose. Children randomised to the chloramphenicol arm received $75 \mathrm{mg} / \mathrm{kg} / \mathrm{d}$ given in three doses every eight hours. Study drugs were procured for all sites from the International Dispensary Association, Amsterdam, Holland. Oxygen was delivered at a rate of $1-2 \mathrm{l} / \mathrm{min}$ by nasal cannula for children with oxygen saturations less than or equal to $90 \%$ (or $\leq 88 \%$ in the two high altitude sites of Yemen and Mexico) and continued for a minimum of three hours. Study doctors assessed the children every six hours using a standardised form, which included vital signs; cardiorespiratory examination; use of oxygen, salbutamol, or antipyretics; and pulse oximetry. If the doctors detected a treatment failure or if they thought that for any reason a change in management was indicated, this was reviewed with the site clinical investigator before a decision was made. An evaluation form was completed at 48-60 hours after randomisation and again at 5-6 days after randomisation, recording any treatment failures that had occurred to these points.

Once children had completed five days of inpatient care and were improved enough for discharge they received ampicillin plus gentamicin daily as an outpatient. The parenteral gentamicin was given once daily at the outpatient clinic or other sites. Sufficient oral amoxicillin ( $45 \mathrm{mg} / \mathrm{kg} / \mathrm{d}$ divided into three doses) was provided to complete the remainder of the 10 day course. Likewise, children in the oral chloramphenicol arm were also given sufficient drugs $(75 \mathrm{mg} / \mathrm{kg} / \mathrm{d}$ in three doses) to complete a 10 day course of treatment. The primary caregiver gave the children their oral antibiotics. Adherence to these regimens was assessed by pill counts and return of empty drug vials at followup visits. 
Follow-up evaluation was at 10-12 days and 21-30 days after discharge. The children were discharged from the study at the completion of the 21-30 day visit and no further information was collected. If children failed to attend for follow-up study staff attempted to assess them at home.

\section{Study outcomes}

Box 3 provides the definitions of primary and secondary outcomes. Children met the primary outcome of treatment failure after five days of admission if any of the events in the box occurred at any point after randomisation. Any change in antibiotic treatment during this period resulted in classification as treatment failure and the need to change the regimen was assessed clinically and throughout the entire five day period, not just at the end of five days of treatment. The study protocol did not permit modifications of the antibiotic regimen. We used the same definitions and approach for the secondary outcomes of treatment failure as defined in box 3 by 48 hours (allowing data to be collected up to 60 hours) and treatment failure plus relapse (hypoxaemic pneumonia) by day 10 (allowing data to be collected up to day 12) and by day 30 (allowing data to be collected between study days 2130).

When the study physician suspected treatment failure (see box 3), the physician contacted the principal investigator or coinvestigator for confirmation. At that time the antibiotic was changed and other appropriate treatment provided. Additional chest radiographs, blood counts, blood cultures, and other laboratory tests to aid patient management according to clinical judgment and the usual practices of the participating site were obtained. Broad guidelines for the management of children who failed study treatment were:

\section{Box 3: Primary and secondary outcome measures}

\section{Primary outcome: treatment failure by five days after admission}

New development or persistence of at least two of the following: inability to drink; tachypnoea ( $\geq 50$ breaths/min in children aged $2-11$ months and $\geq 40$ breaths/min in children aged 12-59 months), and abnormally sleepy or difficult to wake

Development or diagnosis of any of the following: bacterial meningitis, empyema, septic shock, renal failure, or newly diagnosed comorbid conditions

Serious adverse drug reaction

Modification of antibiotic treatment

Voluntary withdrawal or absconding

Death

\section{Secondary outcomes}

Treatment failure as defined above at 48-60 hours

Treatment failure as defined above plus relapse (hypoxaemic pneumonia at 10-12 days and 21-30 days, with oxygen saturations $\leq 90 \%$, or $\leq 88 \%$ in the two high altitude sites in Mexico and Yemen)

Death by 30 days after enrolment

Bacterial pathogens isolated from blood or other sterile sites

Antimicrobial susceptibility of the isolated pathogens

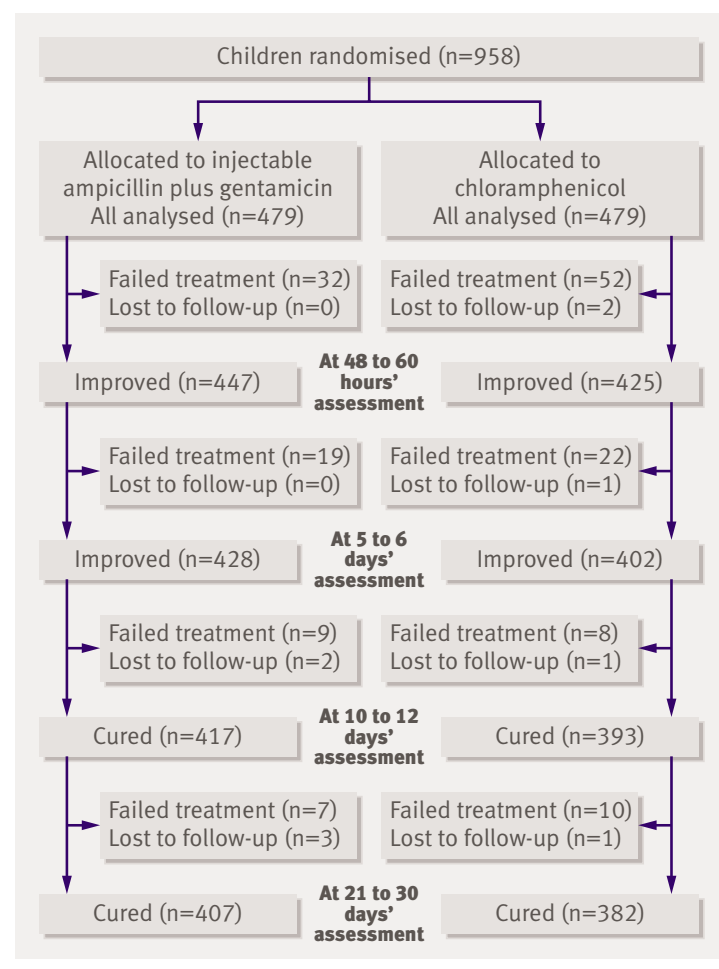

Fig 1 Trial profile

Staphylococcal pneumonia -Cloxacillin or oxacillin $(25-50 \mathrm{mg} / \mathrm{kg}$ intravenously every six hours) were added to the regimen. The duration of treatment to be at least two weeks. Empyema was managed with chest tube drainage.

Pneumocystis carinii (now Pneumocystis jiroveci) pneumonia - Cotrimoxazole (with trimethoprim $20 \mathrm{mg} / \mathrm{kg} / \mathrm{d}$ in two divided doses) and steroids were added to the treatment regimen. The duration of treatment was for at least two weeks.

Non-responsive Gram negative infection-If infection with Gram negative bacilli unresponsive to the study regimen was suspected on the basis of clinical deterioration or development of shock, a third generation cephalosporin such as cefotaxime $(100-200 \mathrm{mg} /$ $\mathrm{kg} / \mathrm{d}$ in four divided doses) or ceftriaxone (100$150 \mathrm{mg} / \mathrm{kg} / \mathrm{d}$ in a single dose) was used. Ceftriaxone was provided by the study.

Mechanical ventilation-Mechanical ventilation was provided, when available, to patients with treatment failure and persistent cyanosis while receiving supplemental oxygen.

\section{Laboratory methods}

Standard microbiological techniques ${ }^{31}$ were used to isolate and identify $S$ pneumoniae and $H$ influenzae. The minimum inhibitory concentration of ampicillin, gentamicin, and chloramphenicol for both Hinfluenzae and Spneumoniae was determined by E test according to the manufacturer's instructions (AB Biodisk, Solna, Sweden). 
Data management procedures

Data were double entered and validated locally with CENTRY software (US Census Bureau, Washington, DC). We sent original copies of the data to the Data Coordinating Center at Boston University, where the electronic data were cleaned and discrepancies resolved.

\section{Statistical analysis}

The sample size of 1182 participants was based on finding a $30 \%$ or greater reduction in treatment failure with ampicillin plus gentamicin compared with an expected $25 \%$ baseline failure rate with chloramphenicol, ${ }^{2732-35}$ a $1: 1$ allocation ratio, $80 \%$ power, an $\alpha$ level of 0.05 , and two planned interim analyses for early stopping with O'Brien-Fleming end points. ${ }^{3637}$

We analysed the data using SAS software. PROC FREQ was used to calculate relative risks and 95\% confidence intervals. To identify risk factors predictive of treatment failure by day 5 and death by day 30 , we

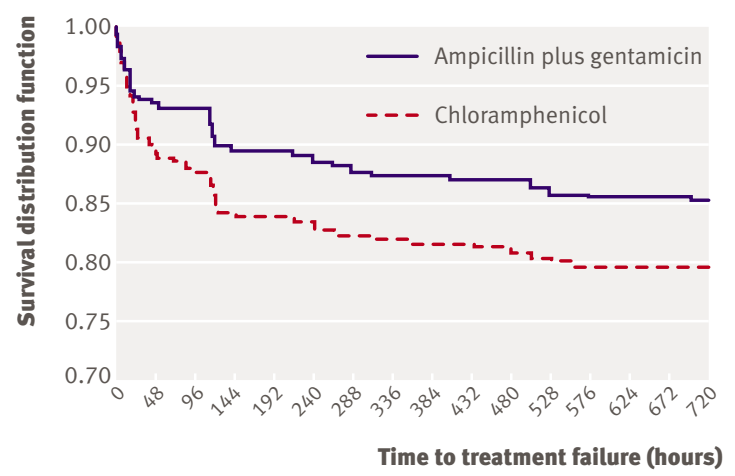

Fig 2 Time to treatment failure

selected a group of factors-immunisation status, sex, hypoxaemia (oxygen saturation $\leq 90 \%$, or $\leq 88 \%$ in the two high altitude sites in Mexico and Yemen), blood glucose, central cyanosis, age, weight for age $\mathrm{z}$ score, and breastfeeding status - and we calculated relative risks. We then included all variables with statistically

Table 2 | Baseline comparison between children aged 2-59 months with very severe pneumonia allocated to receive chloramphenicol or ampicillin plus gentamicin. Values are numbers (percentages) of children unless stated otherwise

\begin{tabular}{|c|c|c|}
\hline Characteristic & Chloramphenicol arm $(n=479)$ & Ampicillin plus gentamicin arm $(n=479)$ \\
\hline Boys & $285 / 479(59)$ & $303 / 479(63)$ \\
\hline Mean (SD) age (months) & $7.9(8.03)$ & $8.0(8.13)$ \\
\hline Breastfeeding* & $381 / 455(84)$ & $367 / 450(82)$ \\
\hline Immunisation status up to date & $321 / 470(68)$ & $324 / 469(69)$ \\
\hline Antibiotic use in previous 24 hours & $154 / 477(32)$ & $167 / 473(35)$ \\
\hline Weight for age less than $-3 \mathrm{z}$ score & $59 / 478(12)$ & $67 / 477(14)$ \\
\hline Median (interquartile range) temperature $\left({ }^{\circ} \mathrm{C}\right)$ & $37.5(37-38)$ & $37.5(37-38)$ \\
\hline Median (interquartile range) heart rate (bpm) & $160.0(146-172)$ & $160.0(144-177)$ \\
\hline $\begin{array}{l}\text { Median (interquartile range) systolic blood } \\
\text { pressure }(\mathrm{mm} \mathrm{Hg})\end{array}$ & $90.0(84-100)$ & $90.0(82-100)$ \\
\hline \multicolumn{3}{|l|}{ Breathing rate: } \\
\hline Fast $†$ & $219 / 479(46)$ & $218 / 479(46)$ \\
\hline Very fastł & $251 / 479(52)$ & $243 / 479(51)$ \\
\hline Median (interquartile range) oxygen saturation & $88.0(80-91)$ & $88.0(80-92)$ \\
\hline Abnormally sleepy & $93 / 479$ (19) & $74 / 479(15)$ \\
\hline Convulsions & $7 / 479(1)$ & $4 / 479(1)$ \\
\hline Central cyanosis & $123 / 479(26)$ & $119 / 479(25)$ \\
\hline Dehydration & $58 / 479(12)$ & $57 / 479(12)$ \\
\hline Signs of shock & $16 / 477(3)$ & $16 / 478(3)$ \\
\hline Lower chest indrawing & $447 / 476(94)$ & $446 / 474(94)$ \\
\hline \multicolumn{3}{|l|}{ Haemoglobin level $(\mathrm{g} / \mathrm{l})$ : } \\
\hline$<60$ & 4/479 (1) & $5 / 479(1)$ \\
\hline $60-90$ & $104 / 479(22)$ & $112 / 479(23)$ \\
\hline Median (interquartile range) total leucocyte count & $12000(9000-15575)$ & $12000(8900-16000)$ \\
\hline \multicolumn{3}{|l|}{ Blood glucose level $(\mathrm{mmol} / \mathrm{l})$ : } \\
\hline$\ll 3.3$ & $265 / 423(63)$ & $272 / 429(63)$ \\
\hline 3.3-4.4 & $28 / 423(7)$ & $32 / 429(7)$ \\
\hline$\geq 4.5$ & $130 / 423(31)$ & $125 / 429(29)$ \\
\hline Positive for respiratory syncytial virus§ & $25 / 365(7)$ & $22 / 359(6)$ \\
\hline
\end{tabular}

No patient had malaria.

*Number of children aged less than 24 months.

tRespiratory rate $\geq 50$ breaths per minute for children aged $2-11$ months and $\geq 40$ but $<70$ breaths per minute for children aged $2-59$ months.

$\ddagger$ Respiratory rate $\geq 70$ breaths per minute.

$\S$ Number of children who had nasopharyngeal aspirates taken. 
significant relative risks in a multivariate logistic regression model built using a backward elimination procedure with PROC LOGISTIC. Treatment group and study site were forced into the model and we retained all variables with a Wald Pvalue of 0.20 or less. We used the GLIMMIX macro to calculate the final multivariate models, in which study site was included as a random effect. Because diagnostics are not available for the random effects model we report model diagnostics (area under the receiver operating curve characteristic and Hosmer and Lemeshow goodness of fit test) for a fixed effects model.

\section{RESULTS}

Enrolment of children occurred between August 2000 and April 2004. The data safety monitoring board ended accrual at the Zambia site after 23 enrolments (2.4\% of total) in November 2001 because of high mortality; this was possibly due to HIV/AIDS. The Ecuador site was added in March 2003 to augment enrolment. A total of 958 children aged 2-59 months with very severe pneumonia were randomised: 479 to ampicillin plus gentamicin and 479 to chloramphenicol (fig 1). Enrolment was discontinued before full study accrual owing to funding limitations, which prevented the extension of activities through another season of acute respiratory tract infections. Table 1 shows the number of children included from each study site, and table 2 shows their baseline characteristics. No statistically significant differences in the baseline characteristics were seen between the two treatment groups. All randomised children were included in the intention to treat analysis for the primary outcome of treatment failure at five days. Overall compliance with treatment was 95\%: $94.4 \%$ of children in the chloramphenicol group and $96.2 \%$ in the ampicillin plus gentamicin group.

\section{Primary outcome: treatment failure at five days}

Of the total $131(13.6 \%)$ children who failed treatmen by day 5 , the cumulative rate was higher among those assigned to the chloramphenicol group (relative risk $1.43,95 \%$ confidence interval 1.03 to 1.97 ; table 3 ). Numerous children had more than one reason for failure but only one was chosen for the study; either the first condition to appear or the most severe if two or

Table 3|Cumulative treatment failures by specific causes at 5, 10, and 21 days and treatment arms for children aged 2-59 months with very severe pneumonia. Values are numbers (percentages) of children unless stated otherwise

\begin{tabular}{|c|c|c|c|c|c|c|c|c|c|}
\hline \multirow[b]{2}{*}{ Outcome } & \multicolumn{3}{|c|}{ Cumulative treatment failure at 5 days } & \multicolumn{3}{|c|}{ Cumulative treatment failure at 10 days } & \multicolumn{3}{|c|}{ Cumulative treatment failure at 21 days } \\
\hline & $\begin{array}{l}\text { Chloram- } \\
\text { phenicol arm } \\
(n=479)\end{array}$ & $\begin{array}{l}\text { Ampicillin } \\
\text { plus } \\
\text { gentamicin } \\
\text { arm }(n=479)\end{array}$ & $\begin{array}{l}\text { Relative } \\
\text { risk }(95 \% \\
\text { Cl) }\end{array}$ & $\begin{array}{l}\text { Chloram- } \\
\text { phenicol arm } \\
(n=479)\end{array}$ & $\begin{array}{l}\text { Ampicillin } \\
\text { plus } \\
\text { gentamicin } \\
\text { arm }(n=479)\end{array}$ & $\begin{array}{l}\text { Relative } \\
\text { risk ( } 95 \% \\
\text { CI) }\end{array}$ & $\begin{array}{l}\text { Chloram- } \\
\text { phenicol arm } \\
(\mathrm{n}=479)\end{array}$ & $\begin{array}{l}\text { Ampicillin } \\
\text { plus } \\
\text { gentamicin } \\
\text { arm }(n=479)\end{array}$ & $\begin{array}{c}\text { Relative } \\
\text { risk }(95 \% \\
\text { Cl) }\end{array}$ \\
\hline Total & $77(16)$ & $54(11)$ & $\begin{array}{l}1.43(1.03 \\
\text { to } 1.97)\end{array}$ & $92(19)$ & $67(14)$ & $\begin{array}{l}1.37(1.03 \\
\text { to } 1.83)\end{array}$ & $103(22)$ & $77(16)$ & $\begin{array}{c}1.34(1.02 \\
\text { to } 1.75)\end{array}$ \\
\hline $\begin{array}{l}\text { Persistence or worsening of } \\
\text { very severe pneumonia }\end{array}$ & $14(3)$ & $17(4)$ & $\begin{array}{l}0.82(0.41 \\
\text { to } 1.65)\end{array}$ & $15(3)$ & $19(4)$ & $\begin{array}{l}0.79(0.41 \\
\text { to } 1.54)\end{array}$ & $17(4)$ & $20(4)$ & $\begin{array}{l}0.85(0.45 \\
\text { to } 1.60)\end{array}$ \\
\hline Death & $15(3)$ & $9(2)$ & $\begin{array}{l}1.67(0.74 \\
\text { to } 3.77)\end{array}$ & $15(3)$ & $9(2)$ & $\begin{array}{c}1.67(0.74 \\
\text { to } 3.77)\end{array}$ & $15(3)$ & $9(2)$ & $\begin{array}{c}1.67(0.74 \\
\text { to } 3.77)\end{array}$ \\
\hline Voluntary withdrawal & $3(1)$ & $2(0)$ & $\begin{array}{c}1.50(0.25 \\
\text { to } 8.94)\end{array}$ & $5(1)$ & $4(1)$ & $\begin{array}{l}1.25(0.34 \\
\text { to } 4.63)\end{array}$ & $7(1)$ & $7(1)$ & $\begin{array}{c}1.00(0.35 \\
\text { to } 2.83)\end{array}$ \\
\hline Antibiotic changed & $45(9)$ & $26(5)$ & $\begin{array}{l}1.73(1.09 \\
\text { to } 2.76)\end{array}$ & $57(12)$ & $35(7)$ & $\begin{array}{l}1.63(1.09 \\
\text { to } 2.43)\end{array}$ & $64(13)$ & $41(9)$ & $\begin{array}{c}1.56(1.08 \\
\text { to } 2.26)\end{array}$ \\
\hline \multicolumn{10}{|l|}{$\begin{array}{l}\text { Reason for changing antibiotic: } \\
*\end{array}$} \\
\hline $\begin{array}{l}\text { Persistence of one } \\
\text { danger sign }\end{array}$ & $18(4)$ & $9(2)$ & $\begin{array}{l}2.00(0.91 \\
\text { to } 4.41)\end{array}$ & $18(4)$ & $9(2)$ & $\begin{array}{l}2.00(0.91 \\
\text { to } 4.41)\end{array}$ & $18(4)$ & $9(2)$ & $\begin{array}{c}2.00(0.91 \\
\text { to } 4.41)\end{array}$ \\
\hline $\begin{array}{l}\text { Bacterial } \\
\text { meningitis }\end{array}$ & $3(1)$ & $2(0)$ & $\begin{array}{c}1.50(0.25 \\
\text { to } 8.94)\end{array}$ & $3(1)$ & $2(0)$ & $\begin{array}{l}1.50(0.25 \\
\text { to } 8.94)\end{array}$ & $3(1)$ & $3(1)$ & $\begin{array}{c}1.00(0.20 \\
\text { to } 4.93)\end{array}$ \\
\hline Empyema & $3(1)$ & $2(0)$ & $\begin{array}{l}1.50(0.25 \\
\text { to } 8.94)\end{array}$ & $4(1)$ & $3(1)$ & $\begin{array}{l}1.33(0.30 \\
\text { to } 5.93)\end{array}$ & $4(1)$ & $3(1)$ & $\begin{array}{l}1.33(0.30 \\
\text { to } 5.93)\end{array}$ \\
\hline Septic shock & $14(3)$ & $9(2)$ & $\begin{array}{l}1.56(0.68 \\
\text { to } 3.56)\end{array}$ & $14(3)$ & $9(2)$ & $\begin{array}{l}1.56(0.68 \\
\text { to } 3.56)\end{array}$ & $15(3)$ & $10(2)$ & $\begin{array}{c}1.50(0.68 \\
\text { to } 3.31)\end{array}$ \\
\hline Renal failure & $3(1)$ & $0(0)$ & - & $3(1)$ & $0(0)$ & - & $3(1)$ & $0(0)$ & - \\
\hline $\begin{array}{l}\text { Serious adverse } \\
\text { drug reaction }\end{array}$ & $1(0)$ & $0(0)$ & - & $1(0)$ & $0(0)$ & - & $1(0)$ & $0(0)$ & - \\
\hline $\begin{array}{l}\text { New comorbid } \\
\text { condition }\end{array}$ & $8(2)$ & $5(1)$ & $\begin{array}{c}1.60(0.53 \\
\text { to } 4.86)\end{array}$ & $8(2)$ & $7(1)$ & $\begin{array}{l}1.14(0.42 \\
\text { to } 3.13)\end{array}$ & $11(2)$ & $7(1)$ & $\begin{array}{c}1.57(0.61 \\
\text { to } 4.02)\end{array}$ \\
\hline $\begin{array}{l}\text { Oxygen saturation } \\
<90 \% \text { on room air }\end{array}$ & NA & NA & NA & $7(1)$ & $5(1)$ & $\begin{array}{l}1.40(0.45 \\
\text { to } 4.38)\end{array}$ & $13(3)$ & $9(2)$ & $\begin{array}{c}1.44(0.62 \\
\text { to } 3.35)\end{array}$ \\
\hline Doctor's decision & $6(1)$ & $5(1)$ & $\begin{array}{c}1.20(0.37 \\
\text { to } 3.91)\end{array}$ & $14(3)$ & $10(2)$ & $\begin{array}{l}1.40(0.63 \\
\text { to } 3.12)\end{array}$ & $14(3)$ & $10(2)$ & $\begin{array}{c}1.40(0.63 \\
\text { to } 3.12)\end{array}$ \\
\hline
\end{tabular}

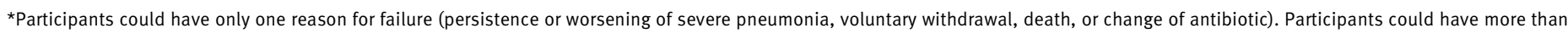
one reason for change of antibiotic. 


\begin{tabular}{|c|c|c|c|c|}
\hline Univariate analysis & Failed treatment by day 5 & Relative risk $(95 \% \mathrm{Cl})$ & Deaths by day 30 & Relative risk $(95 \% \mathrm{Cl})$ \\
\hline \multicolumn{5}{|l|}{ Immunisation status: } \\
\hline Up to date & $54 / 294(18)$ & \multirow{2}{*}{1.58 (1.15 to 2.18$)$} & 28/294 (10) & \multirow{2}{*}{1.71 (1.06 to 2.74$)$} \\
\hline Not up to date & $75 / 645(12)$ & & $36 / 645(6)$ & \\
\hline \multicolumn{5}{|l|}{ Sex: } \\
\hline Girls & $61 / 370(16)$ & \multirow{2}{*}{1.38 (1.01 to 1.90$)$} & $37 / 370(10)$ & \multirow{2}{*}{2.10 (1.31 to 3.37$)$} \\
\hline Boys & $70 / 588(12)$ & & $28 / 588(5)$ & \\
\hline \multicolumn{5}{|c|}{ Hypoxaemia at baseline: } \\
\hline Yes & $102 / 619(16)$ & \multirow{2}{*}{1.93 (1.30 to 2.85$)$} & $53 / 619(9)$ & \multirow{2}{*}{$2.42(1.31$ to 4.46$)$} \\
\hline No & 29/339 (9) & & $12 / 339(4)$ & \\
\hline \multicolumn{5}{|c|}{ Blood glucose level «3.3 mmol/l: } \\
\hline Yes & 69/537 (13) & \multirow{2}{*}{0.88 (0.61 to 1.24$)$} & $32 / 537(6)$ & \multirow{2}{*}{$0.82(0.49$ to 1.37$)$} \\
\hline No & $46 / 315(15)$ & & $23 / 315(7)$ & \\
\hline \multicolumn{5}{|l|}{ Central cyanosis: } \\
\hline Yes & $39 / 242(16)$ & \multirow{2}{*}{1.25 (0.89 to 1.77$)$} & $22 / 242(9)$ & \multirow{2}{*}{1.51 (0.92 to 2.48$)$} \\
\hline No & $92 / 716(13)$ & & $43 / 716(6)$ & \\
\hline \multicolumn{5}{|l|}{ Age (months): } \\
\hline $2-5$ & $73 / 506(14)$ & \multirow{2}{*}{$1.12(0.82$ to 1.55$)$} & $37 / 506(7)$ & \multirow{2}{*}{$1.18(0.73$ to 1.90$)$} \\
\hline $6-59$ & $58 / 452(13)$ & & $28 / 452(6)$ & \\
\hline \multicolumn{5}{|c|}{ Weight for age $z$ score less than -3 : } \\
\hline Yes & $19 / 126(15)$ & \multirow{2}{*}{$1.12(0.71$ to 1.75$)$} & $11 / 126(9)$ & \multirow{2}{*}{1.34 (0.72 to 2.49$)$} \\
\hline No & $112 / 829(14)$ & & $54 / 829(7)$ & \\
\hline \multicolumn{5}{|l|}{ Breastfed: } \\
\hline Yes & $105 / 748(14)$ & \multirow{2}{*}{1.05 (0.68 to 1.62$)$} & $48 / 748(6)$ & \multirow{2}{*}{0.77 (0.43 to 1.40$)$} \\
\hline No & 21/157 (13) & & $13 / 157(8)$ & \\
\hline \multicolumn{5}{|c|}{ Exclusively breastfed: } \\
\hline Yes & $38 / 261(15)$ & \multirow{2}{*}{$1.02(0.66$ to 1.56$)$} & $17 / 261(7)$ & \multirow{2}{*}{$0.82(0.43$ to 1.53$)$} \\
\hline No & $34 / 238(14)$ & & 19/238 (8) & \\
\hline \multicolumn{5}{|c|}{ Received chloramphenicol: } \\
\hline Yes & $77 / 479(16)$ & \multirow{2}{*}{$1.43(1.03$ to 1.97$)$} & 40/479 (8) & \multirow{2}{*}{1.60 (0.99 to 2.59$)$} \\
\hline No & $54 / 479(11)$ & & $25 / 479(5)$ & \\
\hline
\end{tabular}

more were reported simultaneously. Treatment failure at day 5 most commonly occurred as a result of a change in antibiotic treatment $(n=71)$ for several reasons, including a diagnosis of septic shock $(\mathrm{n}=23)$, bacterial meningitis $(n=5)$, empyema $(n=5)$, or other comorbid conditions. Persistence or worsening of very severe pneumonia $(n=31)$ accounted for the second most common cause of failure followed by death $(n=24)$ and the persistence of danger signs $(n=27)$. With the exception of persistence of very severe pneumonia, all of these individual outcomes occurred more commonly in the chloramphenicol group but only change in antibiotic treatment approached statistical significance.

Several factors were associated with treatment failure on univariate analysis: poor immunisation status, being female, baseline hypoxaemia, and receiving chloramphenicol (table 4). By multivariate analysis predictors of treatment failure were hypoxaemia, poor immunisation status, and being female (table 5).

\begin{tabular}{|c|c|c|}
\hline Multivariate analysis & Adjusted odds ratio $(95 \% \mathrm{Cl})^{*}$ & Adjusted odds ratio ( $95 \%$ \\
\hline Immunisations not up to date & $1.71(1.15$ to 2.55$)$ & 1.77 (1.00 to 3.15$)$ \\
\hline Girls & 1.34 (0.91 to 1.97$)$ & 1.95 (1.11 to 3.43$)$ \\
\hline Hypoxaemia & 2.99 (1.86 to 4.80$)$ & $4.7(2.29$ to 9.67$)$ \\
\hline Weight for age $z$ score less than -3 & - & $1.48(0.69$ to 3.19$)$ \\
\hline Received chloramphenicol & $1.44(0.98$ to 2.11$)$ & $1.62(0.91$ to 2.86$)$ \\
\hline
\end{tabular}

*Fixed effects model diagnostics: area under receiver operating curve 0.72 , Hosmer and Lemesho goodness of fit test $P=0.34$, deviance $P=0.15$.

tFixed effects model diagnostics: area under receiver operating curve 0.69 , Hosmer and Lemesho goodness of fit test $P=0.74$, deviance $P=0.65$. 
Secondary outcomes: treatment failure at $\mathbf{4 8}$ hours and 10 and 21 days

By 48 hours after randomisation 87 (9.1\%) children had failed treatment, consisting of $48 \%$ of the total cumulative number of treatment failures. At this early time point an excess of children failed treatment in the chloramphenicol group $(n=54)$ compared with the ampicillin plus gentamicin group $(\mathrm{n}=33$; relative risk $1.6,95 \%$ confidence interval 1.1 to 2.5 ). Similarly, with the exception of persistence of very severe pneumonia, the cumulative total number of children who failed treatment through days 10 and 21 remained higher in the chloramphenicol group, and the distribution of reasons for this remained similar to those observed at day 5 (table 3 ). Figure 2 also shows the time to treatment failure (log rank test $\mathrm{P}=0.024$ ).

\section{Deaths}

Of the 65 deaths, 24 occurred in children after treatment failure had already been declared for other reasons. In 46 cases $(74 \%)$ the child died within 48 hours of enrolment, indicating the rapidly progressive or advanced nature of the illness. By univariate analysis poor immunisation status, being female, and hypoxaemia at presentation were associated with mortality, and by multivariate analysis these factors independently predicted mortality (table 4 ).

\section{Microbiology}

Baseline bacteriological investigations were done on 471 children in the chloramphenicol group and 474 in the ampicillin plus gentamicin group. Of the cultures undertaken at enrolment (958 blood aspirates, 24 cerebrospinal fluid aspirates, and five lung aspirates),
112 (two children had two organisms isolated) gave positive results for pathogenic organisms in all but one aspirate, from the blood (table 6). The two most common organisms isolated were Staphylococcus aureus $(\mathrm{n}=47)$ and Streptococcus pneumoniae $(\mathrm{n}=22)$, followed less commonly by Haemophilus influenzae $(\mathrm{n}=8)$, Escherichia coli $(\mathrm{n}=6)$, and Pseudomonas aeruginosa $(\mathrm{n}=6$; table 6$)$.

On antibiotic sensitivity testing most of the $S$ pneumoniae organisms were susceptible to chloramphenicol (13/14) or ampicillin (15/16), and all were susceptible to third generation cephalosporins. By contrast, only half $(19 / 37)$ of the $S$ aureus isolates exhibited in vitro susceptibility to chloramphenicol and $42 \%(16 / 38)$ to ampicillin.

\section{Treatment failure in the presence of bacteraemia}

Treatment failure at 21 days was significantly more likely if bacteraemia with any pathogenic organism was present at enrolment (table 7). The size of the effect and the degree of statistical significance for treatment failure at 21 days and death increased in the presence of $S$ pneumoniae bacteraemia, however, but was not associated with bacteraemia due to $S$ aureus, irrespective of treatment group.

In a subgroup analysis of children with bacteraemia stratified by treatment group (tables 8 and 9), chloramphenicol was associated with a higher risk of treatment failure at 5,10 , and 21 days. No increased risk of treatment failure was, however, found among those children with bacteraemia in the ampicillin plus gentamicin group. The excess risk in the chloramphenicol group occurred in children with $S$ pneumoniae bacteraemia. In this group, treatment failure was three

\begin{tabular}{|c|c|c|c|c|c|c|}
\hline \multirow[b]{2}{*}{ Bacteria } & \multirow[b]{2}{*}{ No of positive isolates } & \multirow{2}{*}{$\begin{array}{l}\text { No of positive cultures } \\
\text { from blood or } \\
\text { cerebrospinal fluid }\end{array}$} & \multicolumn{4}{|c|}{ Not susceptible to antibiotic ${ }^{\star} /$ No tested } \\
\hline & & & Chloramphenicol & Gentamicin & Ampicillin & $\begin{array}{l}\text { Third generation } \\
\text { cephalosporin }\end{array}$ \\
\hline Streptococcus pneumoniae & 22 & $21 \dagger$ & $13 / 14$ & $12 / 17$ & $15 / 16$ & $12 / 12$ \\
\hline Haemophilus influenzae & 8 & 8 & $6 / 7$ & $5 / 5$ & $6 / 7$ & $6 / 6$ \\
\hline Staphylococcus aureus & 47 & $45 \ddagger$ & $19 / 37$ & $29 / 45$ & $16 / 38$ & $10 / 40$ \\
\hline Klebsiella pneumoniae & 3 & 3 & $1 / 1$ & $2 / 2$ & $1 / 2$ & $1 / 1$ \\
\hline Escherichia coli & 6 & 6 & $1 / 2$ & $3 / 4$ & $1 / 4$ & $4 / 4$ \\
\hline Salmonella spp & 5 & 5 & $5 / 5$ & $5 / 5$ & $5 / 5$ & $4 / 4$ \\
\hline Enterobacter aerogenes & 1 & 1 & $1 / 1$ & $0 / 1$ & $0 / 0$ & $1 / 1$ \\
\hline Pseudomonas aeruginosa & 6 & $5 \ddagger$ & $1 / 2$ & $3 / 3$ & $0 / 2$ & $0 / 3$ \\
\hline Acinetobacter spp & 5 & 5 & $2 / 4$ & $2 / 4$ & $1 / 4$ & $0 / 2$ \\
\hline Morganella spp & 1 & 1 & $1 / 1$ & $1 / 1$ & $0 / 1$ & $0 / 1$ \\
\hline Moraxella spp & 1 & 1 & $1 / 1$ & $1 / 1$ & $1 / 1$ & $0 / 0$ \\
\hline $\begin{array}{l}\text { Flavobacterium } \\
\text { meningosepticum }\end{array}$ & 1 & 1 & $0 / 1$ & $0 / 0$ & $0 / 1$ & $0 / 0$ \\
\hline Pseudomonas spp & 2 & 2 & $2 / 2$ & $2 / 2$ & $0 / 2$ & $0 / 2$ \\
\hline Streptococcus spp & 3 & 3 & $0 / 2$ & $2 / 2$ & $2 / 2$ & $0 / 0$ \\
\hline $\begin{array}{l}\text { Gram negative bacillus } \\
\text { (undetermined) }\end{array}$ & 1 & 1 & $0 / 0$ & $0 / 0$ & $0 / 0$ & $0 / 0$ \\
\hline
\end{tabular}

*Sensitivity according to manufacturer's guidelines (AB Biodisk, Solna, Sweden).

†One case of $S$ pneumoniae isolated from cerebrospinal fluid.

†One pleural fluid sample also positive. 
Table 7| Association between bacteraemia and clinical failure in children aged 2-59 months treated for very severe pneumonia. Values are numbers (percentages) unless stated otherwise

\begin{tabular}{|c|c|c|c|}
\hline Variable & $\begin{array}{l}\text { Treatment failures in children with } \\
\text { bacteraemia }\end{array}$ & $\begin{array}{l}\text { Treatment failures in children } \\
\text { without bacteraemia }\end{array}$ & Relative risk $(95 \% \mathrm{Cl})$ \\
\hline \multicolumn{4}{|c|}{ Any bacteraemia } \\
\hline Follow-up: & $n=110$ & $n=848$ & \\
\hline 48 hours & $8(7)$ & $78(9)$ & 0.79 (0.39 to 1.59$)$ \\
\hline 5 days & 21 (19) & $107(13)$ & 1.51 (0.99 to 2.31$)$ \\
\hline 10 days & $23(21)$ & 125 (15) & 1.42 (0.95 to 2.11$)$ \\
\hline 21 days & $30(27)$ & $139(16)$ & 1.66 (1.18 to 2.34$)$ \\
\hline Death & $11(10)$ & $54(6)$ & 1.57 (0.85 to 2.91$)$ \\
\hline \multicolumn{4}{|c|}{ Staphylococcusaureus bacteraemia $(n=47)$} \\
\hline Follow-up: & $n=47$ & $n=911$ & \\
\hline 48 hours & 0 & $86(9)$ & \\
\hline 5 days & $6(13)$ & $122(13)$ & 0.95 (0.44 to 2.05$)$ \\
\hline 10 days & $6(13)$ & $142(16)$ & $0.82(0.38$ to 1.76$)$ \\
\hline 21 days & 9 (19) & $160(18)$ & 1.10 (0.60 to 1.99$)$ \\
\hline Death & 0 & $65(7)$ & - \\
\hline \multicolumn{4}{|c|}{ Streptococcus pneumoniae bacteraemia } \\
\hline Follow-up: & $n=21$ & $n=937$ & \\
\hline 48 hours & $3(14)$ & $83(9)$ & 1.61 (0.55 to 4.69$)$ \\
\hline 5 days & $5(24)$ & $123(13)$ & 1.81 (0.83 to 3.97$)$ \\
\hline 10 days & $5(24)$ & $143(15)$ & 1.56 (0.72 to 3.40$)$ \\
\hline 21 days & $8(38)$ & $161(17)$ & 2.22 (1.26 to 3.89$)$ \\
\hline Death & $5(24)$ & $60(6)$ & $3.72(1.67$ to 8.30$)$ \\
\hline
\end{tabular}

to four times more likely at any of the study end points, and death was nearly six times more likely. By comparison, bacteraemia due to $S$ aureus or $S$ pneumoniae was not associated with higher treatment failure or death in the ampicillin plus gentamicin group.

\section{DISCUSSION}

In our randomised controlled trial of injectable chloramphenicol compared with injectable ampicillin plus gentamicin for the treatment of very severe pneumonia in children aged 2-59 months, children who received chloramphenicol were more likely to experience treatment failure than those who received ampicillin plus gentamicin. A trend to higher treatment failure in the chloramphenicol group was evident after 24 hours of treatment (fig 2). Of particular concern are the adverse outcomes of treatment failure and death when children develop bacteraemia due to Streptococcus pneumoniae. Although the most common isolate from sterile sites was Staphylococcus aureus, optimally treated with a penicillinase resistant antibiotic such as cloxacillin, our findings indicate that very severe pneumonia due to this organism may be adequately treated with chloramphenicol or ampicillin plus gentamicin (gentamicin does have activity against $S$ aureus). The high rate of $S$ aureus found in blood was unexpected. It might have been a contaminant in some cases although we did provide training in an aseptic technique for obtaining blood cultures and this procedure was evaluated by the study monitors during site visits.

The clear benefit we observed among children receiving ampicillin plus gentamicin in the presence of confirmed $S$ pneumoniae bacteraemia occurred despite a high degree of in vitro antimicrobial susceptibility to both chloramphenicol and ampicillin. Only half of the $S$ pneumoniae isolates were tested for antimicrobial sensitivity to the study drug, however, and it is possible, although unlikely, that a high degree of resistance to chloramphenicol among the untested isolates accounts for our findings. Alternatively, this might constitute further evidence that in vitro antimicrobial susceptibility testing may not correlate closely with clinical outcome of bacterial pneumonia. $^{18-21}$

In addition to being one of the commonest causes of childhood pneumonia, $S$ pneumoniae is also one of the more common causes of meningitis - often occurring concurrently with pneumonia. ${ }^{38-40}$ It is possible that some children in this study who presented with very severe pneumonia due to $S$ pneumoniae also had meningitis. Although no child with suspected meningitis was admitted to this study, in a previous trial of very severe pneumonia, $13 \%$ of a similar group of children in Papua New Guinea had meningitis during the course of illness. ${ }^{28}$ In our study the bacteriostatic properties of chloramphenicol might have been insufficient to kill S pneumoniae organisms in the central nervous system, thus accounting for the higher failure and death rate in this group. ${ }^{40}$ Likewise, the bacteriostatic properties of chloramphenicol might have been insufficient to eradicate advanced infection of the lungs with $S$ pneumoniae in children with very severe pneumonia.

Our rate of adverse treatment outcome is consistent with the findings reported in a trial of benzylpenicillin 
plus gentamicin. ${ }^{28}$ The relative risk for an adverse outcome in that study was 1.14 (95\% confidence interval 0.97 to1.47), which falls within the $95 \%$ confidence limits of our study's results; however, we show a larger and statistically significant effect size, with a $43 \%$ relative improvement in treatment failure at five days and a greater than twofold better outcome among children with confirmed bacteraemia due to $S$ pneumoniae at enrolment. Moreover, the bacteriological data reported in the benzylpenicillin plus gentamicin trial were obtained only once children failed initial treatment (to guide change in treatment), whereas our microbiological samples were obtained at baseline, before study treatment had begun. The investigators and members of the data safety monitoring board reviewed the benzylpenicillin plus gentamicin paper after its publication and concluded that it was ethical to continue with our study to tackle some of the limitations of that study. Superiority of ampicillin plus gentamicin was shown until analysis of the final dataset.

Several baseline factors predicted treatment failure on multivariate analysis: poor immunisation status, being female, hypoxaemia, and receiving chloramphenicol. Neither the newer conjugate pneumococcal vaccine nor the older polysaccharide vaccine was routinely used at any of the study sites and could not account for this factor being associated with increased treatment failure. It is more likely that not being up to day with immunisations was a proxy for poor health seeking behaviour, which might have contributed to delay in the onset of seeking care or other non-specific health status behaviours, as evidenced by many deaths occurring within 48 hours of the children's presentation to hospital. Being female was independently associated with higher treatment failure and death, which is similar to other studies of overall mortality ${ }^{41}$ and severity of acute lower respiratory tract infections and mortality. ${ }^{42}{ }^{43}$ Hypoxaemia at presentation was strongly associated with failure, as has been observed in other settings. ${ }^{2844-47}$ The multivariate models adequately fit the study data and had reasonable discriminatory power.

\section{Strengths and limitations of the study}

The strengths of this study are its randomised controlled design using a standardised protocol that was applied across different paediatric populations in seven low income countries. In addition, the microbiological data increase our understanding of the bacteria associated with WHO defined very severe pneumonia in these settings and permit us to determine the treatment failure and death rates by specific organism isolated. Also, the low losses to follow-up in both groups $(<1 \%)$ strengthen confidence in the outcomes and minimise classification error associated with an intention to treat analysis.

Limitations of the study are its non-blinded study design, which may have introduced bias by study doctors' determination of treatment failure, particularly for the specific outcome of change in antibiotic. It was considered unethical to give placebo injections to tackle differences in inpatient antibiotic schedules, however, and it was not possible to adequately blind

Table $8 \mid$ Association between bacteraemia and clinical failure in children aged 2-59 months receiving chloramphenicol for very severe pneumonia

\begin{tabular}{|c|c|c|c|}
\hline Variable & $\begin{array}{l}\text { Treatment failures in children with } \\
\text { bacteraemia }\end{array}$ & $\begin{array}{l}\text { Treatment failures in children } \\
\text { without bacteraemia }\end{array}$ & Relative risk $(95 \% \mathrm{Cl})$ \\
\hline \multicolumn{4}{|c|}{ Any bacteraemia } \\
\hline Follow-up: & $n=56$ & $n=423$ & \\
\hline 48 hours & $6(11)$ & $48(11)$ & 0.94 (0.42 to 2.10$)$ \\
\hline 5 days & $14(25)$ & $63(15)$ & 1.68 (1.01 to 2.79$)$ \\
\hline 10 days & $16(29)$ & $70(17)$ & 1.73 (1.08 to 2.75$)$ \\
\hline 21 days & $21(38)$ & $76(18)$ & 2.09 (1.41 to 3.10$)$ \\
\hline Death & $7(13)$ & $33(8)$ & $1.60(0.74$ to 3.45$)$ \\
\hline \multicolumn{4}{|c|}{ Staphylococcus aureus bacteraemia } \\
\hline Follow-up: & $n=26$ & $n=453$ & \\
\hline 48 hours & 0 & $54(12)$ & \\
\hline 5 days & $4(15)$ & $73(16)$ & $0.95(0.38$ to 2.41$)$ \\
\hline 10 days & $4(15)$ & $82(18)$ & $0.85(0.34$ to 2.14$)$ \\
\hline 21 days & $6(23)$ & $91(20)$ & $1.15(0.56$ to 2.37$)$ \\
\hline Death & 0 & $40(9)$ & - \\
\hline \multicolumn{4}{|c|}{ Streptococcus pneumoniae bacteraemia } \\
\hline Follow-up: & $n=9$ & $n=470$ & \\
\hline 48 hours & $3(33)$ & $51(11)$ & 3.07 (1.18 to 8.02$)$ \\
\hline 5 days & $5(57)$ & $72(15)$ & 3.63 (1.95 to 6.75$)$ \\
\hline 10 days & $5(57)$ & $81(17)$ & $3.22(1.74$ to 5.97$)$ \\
\hline 21 days & $7(78)$ & 90 (19) & $4.06(2.73$ to 6.03$)$ \\
\hline Death & $4(44)$ & $36(8)$ & $5.80(2.62$ to 12.85$)$ \\
\hline
\end{tabular}


Table 9 | Association between bacteraemia and clinical failure in children aged 2-59 months receiving ampicillin plus gentamicin for very severe pneumonia

\begin{tabular}{|c|c|c|c|}
\hline Variable & $\begin{array}{l}\text { Treatment failures in children with } \\
\text { bacteraemia }\end{array}$ & $\begin{array}{l}\text { Treatment failures in children } \\
\text { without bacteraemia }\end{array}$ & Relative risk $(95 \% \mathrm{Cl})$ \\
\hline \multicolumn{4}{|c|}{ Any bacteraemia } \\
\hline Follow-up: & $\mathrm{n}=54$ & $n=425$ & \\
\hline 48 hours & $2(4)$ & $30(7)$ & $0.52(0.13$ to 2.13$)$ \\
\hline 5 days & $7(13)$ & $44(10)$ & 1.25 (0.59 to 2.64$)$ \\
\hline 10 days & $7(13)$ & $55(13)$ & $1.00(0.48$ to 2.09$)$ \\
\hline 21 days & $9(17)$ & $63(15)$ & $1.12(0.59$ to 2.13$)$ \\
\hline Death & $4(7)$ & $21(5)$ & $1.50(0.53$ to 4.20$)$ \\
\hline \multicolumn{4}{|c|}{ Staphylococcus aureus bacteraemia } \\
\hline Follow-up: & $n=21$ & $n=458$ & \\
\hline 48 hours & 0 & $32(7)$ & - \\
\hline 5 days & $2(6)$ & $49(11)$ & 0.89 (0.23 to 3.42) \\
\hline 10 days & $2(6)$ & $60(13)$ & 0.73 (0.19 to 2.77 ) \\
\hline 21 days & $3(14)$ & 69 (15) & 0.95 (0.33 to 2.76$)$ \\
\hline Death & 0 & $25(6)$ & \\
\hline \multicolumn{4}{|c|}{ Streptococcus pneumoniae bacteraemia } \\
\hline Follow-up: & $n=12$ & $n=467$ & \\
\hline 48 hours & 0 & $32(7)$ & - \\
\hline 5 days & 0 & $51(11)$ & - \\
\hline 10 days & 0 & $62(13)$ & - \\
\hline 21 days & $1(8)$ & $71(15)$ & 0.55 (0.08 to 3.62) \\
\hline Death & $1(8)$ & $24(5)$ & $1.62(0.24$ to 11.02$)$ \\
\hline
\end{tabular}

extra study doctors at each site to treatment assignment because of differences in outpatient antibiotic schedules (daily oral amoxicillin plus gentamicin injections $v$ oral chloramphenicol). We therefore developed rigorous criteria for treatment failure, and study monitors who visited each site monitored all treatment failures to ensure that the study was being done according to protocol. Misclassification of pneumonia due to a bacterial cause may have also been present owing to the non-specific nature of the definition of very severe pneumonia. Although this would tend to minimise our power to detect a difference in treatment groups, we none the less detected a statistically significant difference between chloramphenicol and ampicillin plus gentamicin. It should be noted that these findings have limited applicability in areas of high HIV prevalence, where the spectrum of causes for pneumonia is different and includes Pneumocystis jiroveci, ${ }^{4849}$ an organism not covered by either study

\section{WHAT IS ALREADY KNOWN ON THIS TOPIC}

Community acquired very severe pneumonia has high mortality and is caused by a variety of bacterial organisms

Parenteral chloramphenicol is the standard treatment but has not been rigorously tested

\section{WHAT THIS STUDY ADDS}

Streptococcus pneumoniae and Staphylococcus aureus are the most common causes of very severe pneumonia

Ampicillin plus gentamicin is superior to chloramphenicol, especially against $S$ pneumoniae drug. Finally, we determined whether one of our sites (Zambia) that was removed from the trial prematurely because of inadequacy of the treatment regimen in HIV infected children unduly influenced the study results. We concluded that it did not as the proportions of children failing treatment at day 5 were similar after exclusion of the Zambian site: 70 (15\%) failed treatment with chloramphenicol and 50 (11\%) failed treatment with ampicillin plus gentamicin (relative risk $1.40,95 \%$ confidence interval 1.00 to 1.97 ) compared with $16 \%$ v $11 \%(1.43,1.03$ to 1.97$)$ in the entire cohort.

We believe that our study shows clinical superiority of injectable ampicillin plus gentamicin in the treatment of very severe pneumonia in children aged 2-59 months in an urban referral hospital setting, where all patients with very severe pneumonia are expected to be treated. These findings have important implications for updating WHO's global guidelines for the case management of pneumonia, which until now have recommended chloramphenicol as the first line antibiotic treatment for very severe pneumonia.

Contributors: RA, SB, GJB, OF, PH, II, CL, MK-B, WM, MS, S Singhi, DMT, and $\mathrm{SQ}$ conceived and designed the study and developed the protocol. DMT, SQ, and MS monitored the study. S Saha, Muhammad Ruhul Amin, Muhammad Hanif, PL, FS, JE, GM, S Singhi, Pallab Ray, Akashdeep, IM-R, Sandra Villagómez Martínez, II, Jameel ur Rehman Naeem, Ismaeel Shafeeu, ZK, RA, SB, Abdul Hakeem Bawazeer, Abdul Hakeem Al-Silwi, and MK-B implemented the study and collected data. SB, JE, PH, PL, WM, GM, S Saha, S Singhi, DMT, and SQ analysed the data and prepared the manuscript. PH and WM managed and coordinated the data and carried out the statistical analysis.

We thank the following from the participating sites: Ruth Flor, Patricia Parrales, Sebastian Prado, Norma Villamar, Nelson Nieto, and Brenda Mosquera (Ecuador); Lata Kumar and Shailesh Mehta (India); Patricia Arzate (Instituto Nacional De Pediatria, Mexico); Maximilliano Gonzalez 
and Lilliana Martinez (Juarez Hospital, Mexico); Fatum Maktari, Amin MohiEl-din, and Basil Maktari (Yemen). Steering committee: S Saha (Bangladesh); FS (Ecuador); S Singhi (India); IM-R (Mexico); II (Pakistan), ZK (Pakistan); SB (Yemen); MK-B (Zambia); SQ (Switzerland); DMT, BM and JS (Boston, United States); MS (Baltimore, United States); PH (Boston United States). Data safety monitoring board: Ted Colton (Boston University School of Public Health); Elizabeth Barnett (Boston University Medical Center); Christopher Duggan (Boston Children's Hospital and Harvard School of Public Health).

Funding: Department of Child and Adolescent Health and Development, WHO; Center of International Health and Development, Boston University and Johns Hopkins Bloomberg School of Public Health, Baltimore (USAID grant No HRN-A-00-96-90010-00).

Competing interests: None declared.

Ethical approval: This study was approved by the institutional ethical review committees at all study institutions, plus Boston University Schoo of Public Health, Johns Hopkins University Bloomberg School of Public Health, and WHO. A data safety monitoring board reviewed cumulative data once a year. O'Brien Fleming stopping rules were used twice to determine the safety and utility of continuing the study.

Provenance and peer review: Not commissioned; externally peer reviewed.

1 Williams BG, Gouws E, Boschi-Pinto C, Bryce J, Dye C. Estimates of world-wide distribution of child deaths from acute respiratory infections. Lancet Infect Dis 2002;2:25-32.

2 Black RE, Morris SS, Bryce J. Where and why are 10 million children dying every year? Lancet 2003;361:2226-34.

3 WHO. World health report 2005: make every child count. Geneva: WHO, 2005.

4 WHO programme for the control of acute respiratory infections. Technical basis for the WHO recommendations on the management of pneumonia in children at first level health facilities. WHO/ARI/91.20. Geneva: WHO, 1991.

5 WHO. Management of the child with a serious infection or severe malnutrition: guidelines for care at the first-referral level in developing countries. FCH/CAH/00.1. Geneva: WHO, 2000:1-175.

6 Shann F, Barker J, Poore P. Clinical signs that predict death in children with severe pneumonia. Pediatr Infect Dis / 1989;8:852-5.

7 Shann F. Etiology of severe pneumonia in children in developing countries. Pediatr Infect Dis 1986;5:247-52.

8 WHO. Technical bases for the WHO recommendations on the management of pneumonia in children at first level health facilities. WHO Technical Report 2004;WHO/ARI/91.20

9 Duke T, Michael A. Increase in sepsis due to multi-resistant enteric gram-negative bacilli in Papua New Guinea. Lancet 1999;353:2210-1.

10 Mastro TD, Ghafoor A, Nomani NK, Ishaq Z, Anwar F, Granoff DM, et al. Antimicrobial resistance of pneumococci in children with acute lower respiratory tract infection in Pakistan [see comments]. Lancet 1991;337:156-9.

11 Ostroff SM, Harrison LH, Khallaf N, Assaad MT, Guirguis NI, Harrington S, et al. Resistance patterns of Streptococcus pneumoniae and Haemophilus influenzae isolates recovered in Egypt from children with pneumonia. The Antimicrobial Resistance Surveillance Study Group. Clin Infect Dis 1996:23:1069-74.

12 Steinhoff MC. Invasive Haemophilus influenzae disease in India: a preliminary report of prospective multihospital surveillance. IBIS (Invasive Bacterial Infections Surveillance) Group. Pediatr Infect Dis , 1998;17:S172-5.

13 Likitnukul S. Systemic Haemophilus influenzae disease in Thai children. Southeast Asian J Trop Med Public Health 1994;25:672-7.

14 Muhe L, Klugman KP. Pneumococcal and Haemophilus influenzae meningitis in a children's hospital in Ethiopia: serotypes and susceptibility patterns. Trop Med Int Health 1999;4:421-7.

15 Mastro TD, Nomani NK, Ishaq Z, Ghafoor A, Shaukat NF, Esko E, et al. Use of nasopharyngeal isolates of Streptococcus pneumoniae and Haemophilus influenzae from children in Pakistan for surveillance for antimicrobial resistance. Pediatr Infect Dis / 1993;12:824-30.

16 Gratten M, Naraqi S, Hansman D. High prevalence of penicillin insensitive pneumococci in Port Moresby, Papua New Guinea. Lancet $1980 ; 2: 192-5$

17 Klugman KP. Bacteriological evidence of antibiotic failure in pneumococcal lower respiratory tract infections. Eur Respir / Suppl 2002;36:3s-8s.

18 Straus WL, Qazi SA, Kundi Z, Nomani NK, Schwartz B. Antimicrobial resistance and clinical effectiveness of co-trimoxazole versus amoxycillin for pneumonia among children in Pakistan: randomised controlled trial. Pakistan Co-trimoxazole Study Group. Lancet 1998;352:270-4.

19 Deeks SL, Palacio R, Ruvinsky R, Kertesz DA, Hortal M, Rossi A, et al. Risk factors and course of illness among children with invasive penicillin-resistant Streptococcus pneumoniae. The Streptococcus pneumoniae Working Group. Pediatrics 1999;103:409-13.

20 Rios AM, de la Hoz F, Leal AL, Castillo O, Castaneda E. [The impact of antimicrobial resistance and Streptococcus pneumoniae serotype distribution on the mortality of children under 5 years of age with invasive disease]. Rev Panam Salud Publica 1999;5:69-76.

21 Pallares R, Linares J, Vadillo M, Cabellos C, Manresa F, Viladrich PF, et al. Resistance to penicillin and cephalosporin and mortality from severe pneumococcal pneumonia in Barcelona, Spain [see comments] [published erratum appears in N Engl J Med 199514 Dec;333:1655]. N Engl J Med 1995;333:474-80.

22 Qazi SA, Rehman GN, Khan MA. Reduction in acute respiratory infection hospital mortality with standard ari case management. Islamabad, Pakistan, Federal ARI Cell, National ARI Control Programme: The Children Hospital, Institute of Medical Sciences, 1995:1-19.

23 Sazawal S, Black RE. Effect of pneumonia case management on mortality in neonates, infants, and preschool children: a metaanalysis of community-based trials. Lancet Infect Dis 2003;3:547-56.

24 Bahl R, Mishra S, Sharma D, Singhal A, Kumari S. A bacteriological study in hospitalized children with pneumonia. Ann Trop Paediatr 1995;15:173-7.

25 Mulholland EK, Falade AG, Corrah PT, Omosigho C, N'Jai P, Giadom B, et al. A randomized trial of chloramphenicol vs. trimethoprim sulfamethoxazole for the treatment of malnourished children with community-acquired pneumonia. Pediatr Infect Dis J 1995;14:959-65.

26 Pepin J, Demers AM, Mberyo-Yaah F, Jaffar S, Blais C, Somse P, et al. Acute lower respiratory infections among children hospitalized in Bangui, Central African Republic: toward a new case-management algorithm. Trans R Soc Trop Med Hyg 2001;95:410-7.

27 Qazi SA, Rehman GN, Khan MA. Standard management of acute respiratory infections in a children's hospital in Pakistan: impact on antibiotic use and case fatality. Bull World Health Organ 1996;74:501-7.

28 Duke T, Poka H, Dale F, Michael A, Mgone J, Wal T. Chloramphenicol versus benzylpenicillin and gentamicin for the treatment of severe pneumonia in children in Papua New Guinea: a randomised trial. Lancet 2002;359:474-80.

29 Bahwere P, Levy J, Hennart P, Donnen P, Lomoyo W, Dramaix-Wilmet M, et al. Community-acquired bacteremia among hospitalized children in rural central Africa. Int I Infect Dis 2001;5:180-8.

30 WHO. Acute respiratory infections in children: case management in small hospitals in developing countries. WHO/ARI/90.5. Geneva: WHO, 1990.

31 Forrest KV, Jorgensen JH, Murray PR. Manual of clinical microbiology Washington, DC: American Society for Microbiology 2003.

32 Shann F, Barker J, Poore P. Chloramphenicol alone versus chloramphenicol plus penicillin for severe pneumonia in children. Lancet 1985;2:684-6.

33 Mishra S, Kumar H, Anand VK, Patwari AK, Sharma D. ARI control programme: results in hospitalized children. / Trop Pediatr 1993;39:288-92.

34 Deivanayagam N, Nedunchelian K, Ashok TP, Mala N, Sheela D, Rathnam SR. Effectiveness of ampicillin and combination of penicillin and chloramphenicol in the treatment of pneumonias: randomized controlled trial. Indian Pediatrics 1996;33:813-6.

35 Sehgal V, Sethi GR, Sachdev HP, Satyanarayana L. Predictors of mortality in subjects hospitalized with acute lower respiratory tract infections. Indian Pediatr 1997;34:213-9.

36 O’Brien PC, Fleming TR. A multiple testing procedure for clinical trials Biometrics 1979;35:549-56.

37 O'Brien PC. Procedures for comparing samples with multiple endpoints. Biometrics 1984;40:1079-87.

38 Shann F, Gratten M, Germer S, Linnemann V, Hazlett D, Payne R. Aetiology of pneumonia in children in Goroka Hospital, Papua New Guinea. Lancet 1984;2:537-41.

39 Shann F. Bacterial pneumonia: commoner than perceived. Lancet 2001:357:2070-2.

40 Friedland IR, Klugman KP. Failure of chloramphenicol therapy in penicillin-resistant pneumococcal meningitis. Lancet 1992;339:405-8.

41 Khalique N, Sinha SN, Yunus M, Malik A. Early childhood mortalityrural study. J R Soc Health 1993;113:247-9.

42 Spooner V, Barker /, Tulloch S, Lehmann D, Marshall TF, Kajoi M, et al. Clinical signs and risk factors associated with pneumonia in childre admitted to Goroka Hospital, Papua New Guinea. J Trop Pediatr 1989;35:295-300

43 Tupasi TE, Lucero MG, Magdangal DM, Mangubat NV, Sunico ME, Torres CU, et al. Etiology of acute lower respiratory tract infection in children from Alabang, Metro Manila. Rev Infect Dis 1990;12(Suppl 8):S929-39.

44 Addo-Yobo E, Chisaka N, Hassan M, Hibberd P, Lozano JM, Jeena P, et al. Oral amoxicillin versus injectable penicillin for severe 
pneumonia in children aged 3 to 59 months: a randomised multicentre equivalency study. Lancet 2004;364:1141-8.

45 Dyke T, Brown N. Hypoxia in childhood pneumonia: better detection and more oxygen needed in developing countries. BMJ 1994;308:119-20.

46 Onyango FE, Steinhoff MC, Wafula EM, Wariua S, Musia J, Kitonyi J. Hypoxaemia in young Kenyan children with acute lower respiratory infection. [see comments.] BMJ 1993;306:612-5.

47 Lozano JM. Epidemiology of hypoxaemia in children with acute lower respiratory infection. Int J Tuberc Lung Dis 2001;5:496-504.
48

Chintu C, Bhat GJ, Walker AS, Mulenga V, Sinyinza F, Lishimpi K, et al. Co-trimoxazole as prophylaxis against opportunistic infections in HIVinfected Zambian children (CHAP): a double-blind randomised placebo-controlled trial. Lancet 2004;364:1865-71.

49 Ruffini DD, Madhi SA. The high burden of Pneumocystis carinii pneumonia in African HIV-1-infected children hospitalized for severe pneumonia. AIDS 2002;16:105-12.

Accepted: 5 November 2007 